\title{
Correction to: Reliability and validity of the Hospital Anxiety and Depression Scale in an emergency department in Saudi Arabia: a cross-sectional observational study
}

Zohair A. Al Aseri ${ }^{1 *}$, M. Owais Suriya ${ }^{2}$, Hosam A. Hassan ${ }^{1}$, Mujtaba Hasan ${ }^{1}$, Shaffi Ahmed Sheikh ${ }^{3}$, Adel Al Tamimi ${ }^{1}$, Mashhoor Alshathri ${ }^{1}$ and Najeeb Khalid ${ }^{4}$

\section{Correction to: BMC Emerg Med \\ https://doi.org/10.1186/s12873-015-0051-4}

The original article [1] contains an incorrect affiliation. Affiliation \#1 should instead read as the following:

Departments of Emergency Medicine and Critical Care,

King Saud University, College of Medicine, Riyadh,

Saudi Arabia.

\section{Author details}

'Departments of Emergency Medicine and Critical Care, King Saud University, College of Medicine, Riyadh, Saudi Arabia. ${ }^{2}$ Fellow Community Health, College of Medicine, University of Saskatchewan, 107, Wiggins Road, Saskatoon S7N 5E5, Canada. ${ }^{3}$ Department of Family and Community Medicine, College of Medicine King Khalid University Hospital KSU, PO Box 230155, Riyadh 11321, Kingdom of Saudi Arabia. ${ }^{4}$ Cardiff and Vale University Health Board, Cardiff, UK.

Published online: 31 January 2020

\section{Reference}

1. Al Aseri ZA, et al. Reliability and validity of the Hospital Anxiety and Depression Scale in an emergency department in Saudi Arabia: a cross-sectional obsenvational study. BMC Emerg Med. 2015;15:28 https://doi.org/10.1186/s12873-015-0051-4.

Full list of author information is available at the end of the article 